\title{
Factors Influencing Curriculum Leadership of Primary and Secondary School Teachers from the Perspective of Field Dynamic Theory: An Empirical Investigation in China
}

\author{
Junyuan Chen ${ }^{1,+}$, Yanru Yang ${ }^{1,+}$, Fenghua $X u^{1, *}$, Wenzhe $X u^{1}$, Xiaolin Zhang ${ }^{1}$, Yao Wang ${ }^{1}$ and Yishi Zhang ${ }^{2, *}$ \\ 1 School of Education, Central China Normal University, Wuhan 430079, China; \\ chenjunyuan2021@sina.com (J.C.); yangyi997utopia@163.com (Y.Y.); mocca1119@126.com (W.X.); \\ zhangxiaolin729@163.com (X.Z.); wangyaoshiwo@163.com (Y.W.) \\ 2 School of Management, Wuhan University of Technology, Wuhan 430070, China \\ * Correspondence: xufenghua2010@sina.com (F.X.); yszhang@whut.edu.cn (Y.Z.) \\ + Junyuan Chen and Yanru Yang contributed equally to this work and shared the first authorship.
}

check for updates

Citation: Chen, J.; Yang, Y.; Xu, F.; Xu, W.; Zhang, X.; Wang, Y.; Zhang, Y. Factors Influencing Curriculum Leadership of Primary and Secondary School Teachers from the Perspective of Field Dynamic Theory: An Empirical Investigation in China. Sustainability 2021, 13, 12007. https:/ / doi.org/10.3390/su132112007

Academic Editor: Eila Jeronen

Received: 26 September 2021

Accepted: 25 October 2021

Published: 29 October 2021

Publisher's Note: MDPI stays neutral with regard to jurisdictional claims in published maps and institutional affiliations.

Copyright: (c) 2021 by the authors. Licensee MDPI, Basel, Switzerland. This article is an open access article distributed under the terms and conditions of the Creative Commons Attribution (CC BY) license (https:/ / creativecommons.org/licenses/by/ $4.0 /)$.

\begin{abstract}
Teacher curriculum leadership is in urgent demand to promote the sustainable advancement of curriculum reform, and an important guarantee for the sustainable development of students. It is of important theoretical and practical significance to clarify the influencing factors of the use and the development of teachers' curriculum leadership. Based on Lewin's field dynamic theory, this study conducts a multiple linear regression analysis on the data of 19,521 primary and secondary school teachers in 20 provinces of China, and investigates the influencing factors of teacher curriculum leadership from individual and school fields. The results show that individual field factors are the driving force for teachers to exert and develop curriculum leadership. When teachers have internal leading motivation, the school environment becomes an important inducing force. This finding confirms the realistic rationality of the field dynamic theory, and provides a clear direction for formulating relevant policies and practical plans for enhancing teacher curriculum leadership. That is, it is necessary to fully stimulate the internal motivation of teachers for curriculum leadership, but also to create a school environment for teachers to exercise and develop curriculum leadership.
\end{abstract}

Keywords: teacher curriculum leadership; field dynamic theory; influencing factors; teacher professional development

\section{Introduction}

Teacher leadership has always been considered to play an important role in the sustainable promotion of teacher professional development [1-3] and school reform [4], and thus has been widely considered in academic and practical circles. So far, relevant researches have achieved rich results in the conceptualization [5], classifying development level [6], and exploring practical paths [7] of teacher leadership. With the deepening of research, higher-quality studies on teacher leadership have become an urgent need [8]. Clarifying the influencing factors that promote or inhibit teacher leadership and proposing effective strategies for teacher leadership development have increasingly become important issues in the educational field [4]. Therefore, studying the influencing factors of teacher leadership is of great theoretical significance and practical value.

Current researches on the influencing factors of teacher leadership are mainly reflected in three aspects: Firstly, affirming and analyzing the promotion effect of principal's support on teacher leadership. Providing teachers with an appropriate level of autonomy through reasonable administrative management methods and establishing a productive relationship with teachers are an important manifestation of the principal support. Chamberland [9] (p. 104) points out that even if the team has common goals and independent decisionmaking powers, the principal needs to constantly strive to encourage the leadership of 
others. Gigante and Firestone [10] also believe that school administrators' understanding of the leading role of teachers is an effective driving force. Secondly, it is important to clarify the dual roles of the working environment. Studies show that an overwhelming workload is an important factor in hindering the development of teacher leadership [11]. As an important part of teachers' working environment, school culture has an important influence on teachers' leadership. For example, Hart [12] finds, through empirical research on two middle schools, that the health of school culture is a key factor affecting teacher leadership. Brooks [13] and Podjasek [14] (pp. 22-24) further emphasize the influence of school members' shared vision and goals on teacher leadership. In addition, some studies find through qualitative interviews that interpersonal relationships are also an important factor affecting teacher leadership. For example, Brosky [15] points out that the rejection and dissatisfaction of colleagues hinders the improvement of teacher leadership. Zinn [16] (p. 59) also emphasizes that the degree of support received by teachers, the degree of respect among colleagues, and the spirit of teamwork affect the effectiveness of teacher leadership. Thirdly, exploring the influence of teachers themselves on their leadership. Both the principal's support and the working environment are external factors. Teachers should be taken seriously as behavior subjects. Therefore, some scholars begin to pay attention to the influence of teachers on their leadership. For example, Chamberland [9] (p. 104) points out that teachers who are unable to calmly deal with the hierarchical management structure cannot effectively perform their duties. Muiss and Harris [17] and Klinker [18] further state that personal characteristics, such as a lack of confidence and a lack of experience, will make it difficult for teachers to lead. O'Gorman and Hard [19] found through an empirical investigation that teachers' interpersonal skills, creativity, sensitivity, and advocacy are conducive to the improvement of their leadership.

The researches above reflected the academic community's extensive attention to the influencing factors of teacher leadership and laid a solid foundation for subsequent research. However, it is obvious that these studies are based on teacher leadership in a broad sense, but teacher leadership includes multiple practical areas. A recent meta-analysis shows that among the 7 domains of teacher leadership, the improvement of the curriculum, teaching, and evaluation by teachers is most closely related to student academic performance [20]. This shows that it is necessary to further focus on teachers' leading roles and its influencing factors in the curriculum field within the context of teacher leadership, namely teacher curriculum leadership. However, due to the scarcity of focused research on teacher curriculum leadership, the definition of such a term is still incomplete. Therefore, it is necessary to start with the definition of teacher leadership to explore the definition of teacher curriculum leadership. Based on the definition of teacher leadership by scholars such as Sinha [21], Carpenter and Sherretz [22], and Durias [23] (p. 4), this study defines teacher curriculum leadership as the ability of teachers to cooperate with stakeholders in the curriculum field to promote the sustainable optimization of a curriculum and the sustainable development of students and teachers. In addition, studies related to teacher leadership influencing factors rarely adopt theoretical tools to conduct in-depth investigations. Through a combination of the existing literature, it was found that the current fragmented and inductive analysis of the impacting factors of teacher leadership can be better divided into two aspects: the individual and the environment. This is very consistent with Kurt Lewin's field dynamic theory, which emphasizes the influence of the behavior subject and the environment and their interactions in individual actions. Considering this, the research here attempts to explore the influencing factors of teachers' curriculum leadership with the guidance of field dynamic theory in an empirical way, and then proposes effective strategies for improving teachers' curriculum leadership accordingly, hoping to provide a decision-making basis for teachers' professional development and the sustainable advancement of curriculum reform, which may ultimately serve the sustainable development of students. In short, the core questions of this research are: What are the factors that influence the exertion and development of curriculum leadership of primary and middle school teachers? From the perspective of field dynamic theory, what is the specific influence mechanism? 


\section{Theoretical Framework}

\subsection{Kurt Lewin's Field Dynamic Theory}

Kurt Lewin's field dynamic theory is mainly used to explain the changes in the relationship between an individual's behavior and the surrounding environment. It is mainly composed of two core concepts: the "psychological tension system" and the "life space"; the former aims to emphasize the individual's motivation, while the latter highlights the influence of the environment on individual behavior [24]. When expressing the individual's psychological tension system, Lewin believes that only when the needs break the original psychological balance will they cause internal tension, and then produce the behavior of obtaining a new internal balance [24]. Lewin also analyzes individual behavior and the life space generated by the behavior - that is, the "psychological life space" — and believes that the life space can be divided into several areas with portable barriers. "Field" is a concept of physics. Lewin borrowed this concept and transformed it into a "psychological field", thinking that it is a space in which individuals interact with the environment [25] (p. 11). To understand or predict the right behavior, people and their environments must be regarded as a collection of interdependent factors [24]. The totality of these factors is the individual's life space and is expressed by $\mathrm{B}=f(\mathrm{PE})=f(\mathrm{LS})$. Among them, $\mathrm{B}$ represents the individual behavior; $P$ represents the subject of the behavior; $E$ stands for the environment in which the individual is located; LS is the abbreviation of the life space; that is, the individual's behavior is affected by the individual and the environment. The life space consists of the individual, the environment, and the interrelationship between them [26] (pp. 239-240). Individual behaviors occur in space and are influenced by life or space. When analyzing various behaviors, the generation and change of behaviors can be explained from the relationship between people and the environment. Therefore, the occurrence and development of teacher curriculum leadership is not only influenced by the teachers themselves, but is also inseparable from their environment.

\subsection{Analysis Framework}

According to Lewin's field dynamic theory, teacher curriculum leadership is formed by the interaction of individual teachers with their environment. School is the daily working environment of teachers. Numerous studies have revealed the deep coupling relationship between teachers and schools. Therefore, the main factors affecting teacher curriculum leadership can be classified into two categories: individual field factors and school field factors. Assuming that the teacher curriculum leadership is TCL, the subject of curriculum leadership is teacher $\mathrm{P}$, the individual field factor is E1, and the school field factor is E2; then TCL $=f(\mathrm{P} \mathrm{E} 1 \mathrm{E} 2)$ - that is, teachers' curriculum leadership is the function of the above two fields.

\subsubsection{Individual Field Factor Analysis}

Teachers, as the main actors, must meet the following conditions to develop curriculum leadership: Firstly, a higher professional level. Teachers with a high level of professionalism (teachers who have achieved success in classroom teaching) can often establish prestige among all teachers and become "expert teachers" in the eyes of colleagues. Their suggestions are more likely to be adopted by colleagues and then win colleagues' respect and expand their influence [8]. Secondly, curriculum leadership willingness. Harris and Muijs [27] found, through an empirical study, that unwillingness to lead to some extent hinders the teachers in becoming school leaders, because some teachers only regard themselves as classroom practitioners rather than school leaders, and think that the leadership role should be borne by the school management team. Thirdly, the quality of leading others, that is, teachers' trust in colleagues and their ability to be trusted by colleagues [15]. At the same time, teachers' sense of self-efficacy can enable them to better implement curriculum leadership [23] (p. 155). Finally, strong leadership skills, such as self-planning and management skills, interpersonal skills, etc., are inevitable requirements for the development of teacher curriculum leadership $[19,28,29]$. 


\subsubsection{Analysis of School Field Factors}

Most teachers' practices are happening in the school field. Thus, school plays an important role in the generation and development of teacher curriculum leadership. To be clear, firstly, a clear common vision and a school culture of mutual trust among members. Schools lacking a unified vision will inhibit the generation of teacher curriculum leadership [13], and cultivating the trust between colleagues, teachers, and students is a key task within the school [17]. Secondly, a cooperative teacher development community. When team members are unwilling to follow, it is difficult for a teacher to become a successful leader [30]. Again, this is the flat school organization structure. The bureaucratic organizational structure, on the one hand, tends to aggravate the indifference and alienation of the relationship between colleagues, and is not conducive to promoting mutual assistance between them [31] (pp. 16-17); on the other hand, the unidirectional obedience relationship hinders the exertion of the teacher's subjective spirit and inhibits the teacher's autonomy and creativity [32]; a democratic and equal school organizational structure can enable teachers to achieve creative development. Finally, the principal's support for teacher leadership. The principal should become a "leader of teacher leaders", discover teachers with leadership potential, and provide support and opportunities to train them to become leading teachers [33]. For example, daring to empower teachers. Providing an appropriate level of autonomy for teachers to implement curriculum leadership is vital administrative support [2], which helps encourage teachers' leading behavior. Besides, trust and care about teachers' ability and behavior of leadership. Principals who try to encourage, trust, and care about teachers can create a culture that supports teacher leadership abilities, which is very beneficial to teacher leadership [2]. This also involves being good at listening to and communicating with teachers' feelings and experiences in implementing curriculum leadership. Studies have shown that principal's willingness to listen to, understand, and respect the responsibilities and job descriptions of teacher leaders can increase teacher's identity and self-confidence [34] (p. 145). Lastly, a certain degree of reward can improve the enthusiasm of teacher leaders. Borchers [35] (p. 108) believes that recognizing these teacher leading behaviors in some way (material compensation or other ways) is conducive to teacher leadership.

Based on the above analysis, this study constructs an analysis framework for measuring the influencing factors of teacher's curriculum leadership, as shown in Figure 1.

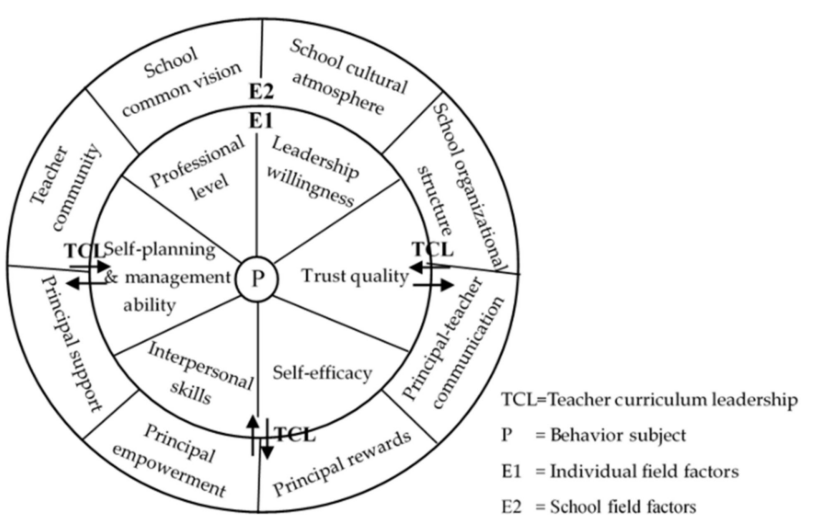

Figure 1. The analytical framework of teacher curriculum leadership influencing factors.

\section{Methodology}

In this study, we investigate and analyze the essential factors that influence Chinese primary and middle school teachers' curriculum leadership drawing upon the field dynamic theory. According to the theoretical framework shown in Section 2, we develop the research instruments from two aspects: the individual field and the school field. Due to the lack of mature questionnaires that could be directly used in this study, we enrich the variables and items under the individual field and school field by referring to a large number of 
relevant literature and questionnaires. Then we use a large-scale nationwide questionnaire survey and a hierarchical regression analysis concerning both the individual field and the school field to clarify the influencing elements and mechanisms for the exertion and development of Chinese teachers' curriculum leadership under the key competencies-driven new curriculum reform.

\subsection{Data Collection and Participants}

The data used in this study mainly come from a survey launched by the "Study on Curriculum Leadership of Primary and Secondary School Teachers" Research Group from January 2020 to April 2021 in Sichuan, Hubei, Guangxi, Shandong, Shanxi, Hunan, Beijing, Ningxia, Guangdong, Xinjiang, Zhejiang, Jiangsu, Guizhou, Chongqing, Hebei, Henan, Shanghai, Anhui, Inner Mongolia, and Qinghai in China. To ensure that the research samples are broadly representative, we adopt the stratified random sampling method. Firstly, 20 provinces including Sichuan, Hubei, and Shandong are selected in the east, middle, and west of China according to the geographical location and economic level; secondly, among the 20 provinces, the more developed and backward cities or regions are selected in a balanced manner according to the level of economic development; then, elementary schools, middle schools, and ordinary high schools are randomly selected from the selected cities; finally, a group survey is conducted by the teachers of the selected schools. Considering the national epidemic prevention and control policy, we use online electronic questionnaires for data collection. A total of 23,915 questionnaires are finally collected, of which 19,521 are valid, and the effective response rate is $81.63 \%$. The sample characteristics are shown in Table 1:

Table 1. Demographic characteristics of the teacher samples.

\begin{tabular}{|c|c|c|c|c|c|}
\hline Characteristics & Number of People (N) & Percentage (\%) & Characteristics & Number of People (N) & Percentage (\%) \\
\hline Gender & & & Chinese & 6027 & 30.9 \\
\hline Female & 5454 & 27.9 & Math & 4905 & 25.1 \\
\hline Male & 14,067 & 72.1 & English & 2461 & 12.6 \\
\hline School location & & & Physics & 608 & 3.1 \\
\hline Urban area & 16,555 & 84.8 & Chemistry & 482 & 2.5 \\
\hline Rural area & 2966 & 15.2 & Biology & 515 & 2.6 \\
\hline Ethnic regions & 6263 & 32.1 & Ethics and Rule of Law & 2295 & 11.8 \\
\hline Non-ethnic regions & 13,258 & 67.9 & Geography & 477 & 2.4 \\
\hline School ranking & & & History/ History and Society & 657 & 3.4 \\
\hline Medium and below & 5256 & 26.9 & Music & 1002 & 5.1 \\
\hline Above medium & 10,868 & 55.7 & Art & 982 & 5.0 \\
\hline Best & 3397 & 17.4 & Sports and Health & 1535 & 7.9 \\
\hline Teaching age & & & Information Technology & 560 & 2.9 \\
\hline $0-5$ years & 5015 & 25.7 & Science & 1176 & 6.0 \\
\hline $6-10$ years & 2711 & 13.9 & Others & 1144 & 5.9 \\
\hline $11-15$ years & 2059 & 10.5 & Position & & \\
\hline 16-20 years & 2113 & 10.8 & None & 6580 & 33.7 \\
\hline 21 years and above & 7723 & 39.1 & class teacher & 7217 & 37.0 \\
\hline School nature & & & $\begin{array}{c}\text { Lesson preparation team } \\
\text { leader }\end{array}$ & 1699 & 8.7 \\
\hline Public school & 18,728 & 95.9 & $\begin{array}{c}\text { Teaching-research team } \\
\text { leader }\end{array}$ & 1868 & 9.6 \\
\hline Private school & 793 & 4.1 & Grade manager & 766 & 3.9 \\
\hline Job title & & & Dean/Deputy dean & 903 & 4.6 \\
\hline Unrated & 2762 & 14.1 & Vice-principal & 492 & 2.5 \\
\hline Third-level teacher & 472 & 2.4 & Principal & 155 & 0.8 \\
\hline Secondary teacher & 5833 & 29.9 & Others & 2670 & 13.7 \\
\hline First-level teacher & 7513 & 38.5 & $\begin{array}{c}\text { Teacher education } \\
\text { background }\end{array}$ & & \\
\hline Advanced teacher & 2909 & 14.9 & Yes & 1648 & 84.5 \\
\hline Senior teacher & 31 & 0.2 & No & 3032 & 15.5 \\
\hline Teaching period & & & Highest degree & & \\
\hline Primary school & 11,268 & 57.7 & Below college degree & 82 & 0.4 \\
\hline Middle school & 5385 & 27.6 & College degree & 2914 & 14.9 \\
\hline High school & 2868 & 14.7 & Bachelor degree & 15,275 & 78.2 \\
\hline Teaching subject & & & Above bachelor degree & 1250 & 6.4 \\
\hline
\end{tabular}




\subsection{Instruments and Variable Definition}

\subsubsection{Instruments}

In the compilation of the questionnaire items, we refer to related questionnaires that are proved to be very reliable, mainly including "Shanghai School Curriculum Leadership" evaluation index system and evaluation points [36], "Teacher Questionnaire of China Education Panel Survey in School Year 2014-2015" launched by China Survey and Data Center, Renmin University of China [37], "Vanderbilt Assessment of Leadership in Education" (VAL-ED) developed by four professors from the Peabody School of Education, Vanderbilt University in the United States [9] (p. 104).

The questionnaire used in this study is composed of three parts: PART I is the demographic characteristics of teachers. The items in this part mainly focus on the background information of the teachers themselves, including gender, teaching age, professional title, position, educational background, highest degree, school location, nature of the school, teaching period, teaching subject (s), and school quality (ranking). Items include singlechoice and multiple-choice questions, corresponding to question 1-12 in the questionnaire. PART II is the measurement of the realistic level of teacher curriculum leadership. This part is based on the three-dimensional model of teacher leadership proposed by Sinha and Hanuscin [21]. Items are set and measured from three dimensions of teacher curriculum leadership views, practices, and identity, corresponding to question 14. (1-29), a Likert 5-point scale is adopted, ranging from "strongly disagree" (1 point) to "strongly agree" (5 points). PART III is to measure the relevant factors that affect teacher curriculum leadership. This part is based on Lewin's field dynamic theory, within the framework shown in Figure 1, indicators and items are set from the two dimensions; namely, the individual field and the school field. Individual field factors are corresponding to question 13 (single-choice form) and 14. (30-34) (Likert 5-point scale). School field factors are measured by items 14 . (35-42) in the form of a Likert 5-point scale. Since China initiated a new round of basic education curriculum reform driven by key competencies in 2014 and updated the ordinary high school curriculum plan and curriculum standards accordingly, this study uses key competencies as a macro background for guiding the development of the questionnaire and penetrates it into the expressions of specific items (See Appendix A for details).

In the reliability test, the Cronbach's $\alpha$ coefficient of the Teacher Curriculum Leadership Scale is 0.967, and the Cronbach's $\alpha$ coefficient of the Individual Field Factors Influencing Teacher Curriculum Leadership Scale is 0.887 , and the Cronbach's $\alpha$ coefficient of the School Field Factors Influencing Teacher Curriculum Leadership Scale is 0.962, the Cronbach's $\alpha$ coefficient of the Teacher's Curriculum Leadership Influencing Factors Scale is 0.958 , and the Cronbach's $\alpha$ coefficient of the total scale is 0.977 . It can be observed that the subscales and the total scale have good internal consistency (see Table 2). In the validity test, the expert judgment method is used to judge the content validity of the questionnaire. Five experts in the field of education and teaching are invited to evaluate the correspondence between the questionnaire and the indicators, the scientific structure, rationality, and language expression of the questionnaire. All the experts confirm that the questionnaire can better reflect the research content. Therefore, the questionnaire used in this study has good reliability and validity.

Table 2. Reliability test of the scales.

\begin{tabular}{ccc}
\hline Measurement Dimension & Internal Consistency Reliability Test (Cronbach's $\boldsymbol{\alpha})$ & Number of Items On the Scale (N) \\
\hline Teacher curriculum leadership & 0.967 & 29 \\
Individual field factors & 0.887 & 5 \\
School field factors & 0.962 & 8 \\
Influencing factors of teacher & 0.958 & 13 \\
curriculum leadership & 0.977 & 42 \\
Total scale & & \\
\hline
\end{tabular}




\subsubsection{Variable Definition}

In this study, teacher curriculum leadership is taken as the dependent variable, and individual field factors and school field factors are taken as independent variables. As analyzed above, the individual field factors include six variables: professional level, leadership willingness, trust quality, self-efficacy, self-planning and management ability, and interpersonal skills. The professional level here is a dummy variable, represented by the highest level of education and teaching awards the teacher has received so far, with "not yet awarded" as the reference group. The remaining 5 are all quantitative variables. The school field factors include eight variables: the school common vision, school cultural atmosphere, teacher community, school organizational structure, principal-teacher communication, principal's support for teacher professional development, principal reward, and principal empowerment, all of which are quantitative variables. The mean and standard deviation of each variable are shown in Table 3.

Table 3. Mean and standard deviation of teacher curriculum leadership and influencing factors $(\mathrm{N}=19,521)$.

\begin{tabular}{cccccc}
\hline Variables. & Mean & SD & Variables & Mean & SD \\
\hline Teacher curriculum leadership & 3.76 & 0.577 & School common vision & 3.86 & 0.727 \\
Individual field factors & & & School cultural atmosphere & Teacher community & 0.723 \\
Leadership willingness & 3.51 & 0.837 & School organizational structure & 4.00 & 0.701 \\
Trust quality & 3.91 & 0.688 & 3.82 & 0.794 \\
Self-efficacy & 3.96 & 0.679 & Principal's support for teacher development & 3.88 & 0.769 \\
Self-planning and management ability & 3.90 & 0.695 & Principal-teacher communication & 3.84 & 0.797 \\
Interpersonal skills & 3.84 & 0.705 & Principal empowerment & 3.78 & 0.805 \\
School field factors & & & Principal reward & 3.82 & 0.785 \\
\hline
\end{tabular}

\subsection{Analysis}

This study applies a hierarchical linear regression model to analyze the influencing factors of teacher curriculum leadership. The specific econometric regression model expressed in the matrix form is:

$$
\boldsymbol{Y}=\boldsymbol{\beta}_{\text {individual }}^{T} \mathbf{X}_{\text {individual }}+\boldsymbol{\beta}_{\text {school }}^{T} \mathbf{X}_{\text {school }}+\boldsymbol{\beta}_{\text {control }}^{T} \mathbf{X}_{\text {control }}
$$

where $Y$ represents the curriculum leadership of elementary and middle school teachers, which is the overall level of teacher curriculum leadership views, teacher curriculum leadership practices, and teacher curriculum leadership identity. According to Lewin's field dynamic theory, teachers' motivation is the most important for the exertion and development of their curriculum leadership, followed by the influence of the environment. Therefore, in the hierarchical linear regression model, the individual variables are input first, with the school field variables following up. $\mathbf{X}_{\text {individual }}$ contains the core explanatory variables from the individual field, i.e., professional level, leadership willingness, trust quality, self-efficacy, self-planning and management ability, and interpersonal skills. $\mathbf{X}_{\text {school }}$ represents another core explanatory variables from the school field, including 8 sub-variables: school common vision, school cultural atmosphere, teacher community, school organizational structure, principal's support, empowerment and rewards, and principal-teacher communication. $\mathbf{X}_{\text {control }}$ represents the control variable set, including gender, teaching age, urban and rural location, ethnic location, school nature, school ranking, teaching period, professional title, professional background, subject background, position background, and highest degree (which are converted into dummy variables when conducting regression).

\section{Results}

Using hierarchical regression analysis, 3 models are obtained (see Table 4). Model 1 is the case where only the control variables are input, and the explanatory power of the model is $3.8 \%$ at this time. Model 2 is the case where the teacher's personal factors are added on the basis of controlling the relevant interference variables. At this time, the 
explanatory power of the model is significantly improved (adjusted $R^{2}$ is $70.5 \%$ ). Model 3 adds variables representing school field factors on the basis of Model 2, and the explanatory power (adjusted $\mathrm{R}^{2}$ ) of the model rises to $72.8 \%$. The results show that the application and development of teachers' curriculum leadership are significantly affected by the comprehensive influence of the individual and the school fields. Next, we will analyze the comprehensive influence of the individual field factors as well as the school field factors on teacher curriculum leadership.

Table 4. Regression results of influencing factors of Chinese teachers' curriculum leadership.

\begin{tabular}{|c|c|c|c|}
\hline \multirow{2}{*}{ Independent Variables } & \multicolumn{3}{|c|}{ Dependent Variable: Teacher Curriculum Leadership } \\
\hline & Model 1 & Model 2 & Model 3 \\
\hline \multicolumn{4}{|l|}{ Control variables } \\
\hline Gender-Male & $0.001(0.281)$ & $-0.011^{* *}(0.157)$ & $-0.011^{* *}(0.151)$ \\
\hline Highest degree-Below college degree & $-0.004(1.829)$ & $-0.007(1.013)$ & $-0.008 *(0.974)$ \\
\hline Highest degree-College degree & $-0.033^{* * *}(0.362)$ & $-0.015^{* * *}(0.202)$ & $-0.014^{* * *}(0.194)$ \\
\hline Highest degree-Above bachelor degree & $0.011(0.498)$ & $-0.001(0.276)$ & $0.001(0.266)$ \\
\hline Teacher education background-Yes & $0.002(0.342)$ & $-0.001(0.190)$ & $0.002(0.182)$ \\
\hline Teaching age $-6-10$ years & $-0.017(0.429)$ & $-0.004(0.241)$ & $-0.004(0.232)$ \\
\hline Teaching age $-11-15$ years & $0.000(0.496)$ & $0.006(0.279)$ & $0.005(0.268)$ \\
\hline Teaching age-16-20 years & $0.000(0.538)$ & $0.012 *(0.302)$ & $0.012 *(0.290)$ \\
\hline Teaching age -21 years and above & $-0.020(0.507)$ & $0.031^{* * *}(0.285)$ & $0.035^{* * *}(0.274)$ \\
\hline School location-Rural & $-0.042^{* * *}(0.348)$ & $-0.019^{* * *}(0.193)$ & $-0.016^{* * *}(0.186)$ \\
\hline School location-Ethnic & $-0.003(0.254)$ & $-0.003(0.141)$ & $-0.001(0.136)$ \\
\hline School nature-Public & $-0.022 * *(0.610)$ & $-0.007(0.338)$ & $-0.008 *(0.326)$ \\
\hline Teaching period-Middle school & $-0.048 * * *(0.290)$ & $-0.028 * * *(0.161)$ & $-0.020^{* * *}(0.155)$ \\
\hline Teaching period-High school & $-0.070 * * *(0.387)$ & $-0.032 * * *(0.216)$ & $-0.015^{* * *}(0.209)$ \\
\hline School ranking-Medium and below & $-0.196^{* * *}(0.370)$ & $-0.048^{* * *}(0.208)$ & $-0.020^{* * *}(0.202)$ \\
\hline School ranking-Above medium & $-0.128^{* * *}(0.328)$ & $-0.033^{* * *}(0.183)$ & $-0.018^{* * *}(0.176)$ \\
\hline Teaching subject-Multidisciplinary & $-0.040^{* * *}(0.317)$ & $-0.013 * * *(0.176)$ & $-0.009 *(0.169)$ \\
\hline Post-With administrative position (s) & $0.020^{* *}(0.255)$ & $0.004(0.142)$ & $0.002(0.137)$ \\
\hline Title-Third-level teacher & $-0.011(0.824)$ & $0.001(0.461)$ & $0.004(0.444)$ \\
\hline Title-Secondary-level teacher & $-0.069^{* * *}(0.426)$ & $-0.008(0.257)$ & $-0.001(0.247)$ \\
\hline Title-First-level teacher & $-0.062 * * *(0.533)$ & $-0.016(0.317)$ & $-0.006(0.305)$ \\
\hline Title-Advanced teacher & $-0.022(0.640)$ & $-0.020 *(0.376)$ & $-0.010(0.362)$ \\
\hline Title-Senior teacher & $0.031^{* * *}(3.005)$ & $0.003(1.675)$ & $0.002(1.610)$ \\
\hline \multicolumn{4}{|l|}{ Individual field factors } \\
\hline Professional level—School level awards & & $0.005(0.286)$ & $0.005(0.275)$ \\
\hline Professional level-County/District level awards & & $0.006(0.256)$ & $0.008(0.246)$ \\
\hline Professional level-Municipal awards & & $0.019 * *(0.273)$ & $0.022 * *(0.262)$ \\
\hline Professional level-Provincial awards & & $0.008(0.313)$ & $0.011 *(0.301)$ \\
\hline Professional level-National awards & & $0.028 * * *(0.331)$ & $0.031^{* * *}(0.319)$ \\
\hline Leadership willingness & & $0.282 * * *(0.100)$ & $0.273^{* * *}(0.098)$ \\
\hline Trust quality & & $0.202 * * *(0.151)$ & $0.160 * * *(0.149)$ \\
\hline Self-efficacy & & $0.108^{* * *}(0.165)$ & $0.083^{* * *}(0.160)$ \\
\hline Self-planning and management ability & & $0.131^{* * *}(0.156)$ & $0.093^{* * *}(0.152)$ \\
\hline Interpersonal skills & & $0.272 * * *(0.149)$ & $0.152 * * *(0.163)$ \\
\hline \multicolumn{4}{|l|}{ School field factors } \\
\hline School common vision & & & $0.135^{* * *}(0.184)$ \\
\hline School culture & & & $0.017(0.202)$ \\
\hline Teacher community & & & $0.046^{* * *}(0.175)$ \\
\hline School organizational structure & & & $-0.027^{* * *}(0.175)$ \\
\hline Principal's support for teacher development & & & $0.000(0.204)$ \\
\hline Principal-teacher communication & & & $0.047^{* * *}(0.186)$ \\
\hline Principal empowerment & & & $0.056^{* * *}(0.155)$ \\
\hline Principal reward & & & $0.016 *(0.146)$ \\
\hline Sample size & & 19,521 & \\
\hline Adjusted $\mathrm{R}^{2}$ & 0.038 & 0.705 & 0.728 \\
\hline
\end{tabular}

${ }^{*} p<0.05 .{ }^{* *} p<0.01 .{ }^{* * *} p<0.001$. The number in the bracket denotes the standard error. 


\subsection{Individual Field Factors Have Significant Positive Impacts on Teacher Curriculum Leadership}

As shown in Model 2, in the case of controlling gender, highest degree, professional background, teaching age, school location, school nature, teaching stage, school ranking, teaching subject (s), position (s), and title, the 6 factors that reflect teacher's personal factors together explain $70.5 \%$ of the variance of teacher curriculum leadership. Moreover, each variable has a significant positive impact on teacher curriculum leadership. Among them, leadership willingness has the highest explanatory power $(\beta=0.282, p<0.001)$, indicating that teacher's leadership willingness level best predicts the level of curriculum leadership. Since the standardized regression coefficient is positive, it indicates that the stronger the teacher curriculum leadership willingness, the higher the teacher curriculum leadership level. The rest are interpersonal skills, trust quality, self-planning and management skills, self-efficacy, and professionalism. Since the level of professionalism is a dummy variable, the report of its explanatory power needs to refer to the reference group. The reference group for the professional level variable in this study is set as "not yet awarded". Results show that teachers who have won municipal and national awards demonstrate a higher level of curriculum leadership compared with those who have not yet received any education or teaching awards. However, teachers with the other awarding levels (school, district/county, and provincial level) reveal no significant difference in curriculum leadership level compared with the teachers who have not yet received any awards.

\subsection{The Comprehensive Influence of Individual Field Factors and School Field Factors on Teacher Curriculum Leadership}

As shown in Model 3, when the disturbance variables are controlled, the 6 variables reflecting the teacher's personal factors and the 8 variables reflecting the school field factors together explain $72.8 \%$ of the variance of the teacher's curriculum leadership, showing that the model explanatory power increases by $2.3 \%$ when school field factors are added.

In terms of schools, among the 8 variables invested, only 6 factors reach the significant level; namely, the school common vision, teacher community, school organizational structure, principal-teacher communication, principal empowerment, and principal rewards. Among them, the school common vision has the strongest explanatory power, with a standardized regression coefficient of $0.135(p<0.001)$. The rest are principal empowerment, principal-teacher communication, teacher community, school organizational structure, and principal rewards. From the orientation of prediction, the influence of school organizational structure on teacher curriculum leadership is negative, and the rest are positive. This shows that a high degree of agreement among the school-running philosophy, training goals, and curriculum goals is particularly important for the development of teacher curriculum leadership. In addition, the principal's curriculum empowerment, exchanges with teachers on curriculum improvements, appropriate rewards for teachers, and mutual help among teachers all have significant positive impacts on the improvement of teacher curriculum leadership, but the school organizational structure (that is, "school management will fully absorb the opinions of teachers when making curriculum decisions") has a significant negative impact on teacher curriculum leadership. In terms of teachers, after adding school field factors, all variables of teachers' personal factors are adjusted, and the explanatory power decreases. For example, the explanatory power of teachers' willingness for leading becomes $27.3 \%$. However, the explanatory powers of most variables of teacher's individual field factors are still higher than those of the variables of school field factors.

\section{Discussion}

Through a hierarchical regression analysis on the data of 19,521 primary and middle school teachers in China, this study shows that the teacher's curriculum leadership is simultaneously affected by the subject and the school environment, and the subject has a greater impact on his/her curriculum leadership. These are highly consistent with Lewin's field dynamic theory. This section will focus on this discovery, combined with 
field dynamic theory and related literature, to carry out in-depth discussions, and then propose strategies to improve teachers' curriculum leadership.

\subsection{Field Analysis of Influencing Factors of Teacher Curriculum Leadership}

\subsubsection{Teachers' Willingness to Lead Is the Driving Force behind Their Curriculum} Leadership Development

Model 2 and Model 3 together show that teachers themselves are the core explanatory variables that affect their curriculum leadership. More specifically, teacher's willingness to lead is the driving force for the use and improvement of curriculum leadership. No matter in Model 2 or Model 3 with the addition of school field factors, teachers' curriculum leadership willingness has the strongest explanatory power $(\beta=0.282, p<0.001$ in Model 2; $\beta=0.273, p<0.001$ in Model 3), indicating that compared with the remaining explanatory variables, whether a teacher exerts or develops curriculum leadership depends more on whether the teacher has the corresponding subjective desire. This conclusion further confirms the field dynamic theory. According to the field dynamic theory, whether the external environment becomes a motivating factor for individual behavior depends on the magnitude and direction of the internal dynamics. If the individual lacks behavioral motivation, external factors will not be able to boost the individual, and may even result in the opposite effect [38]. In terms of the overall comparison between teacher individual field factors and school field factors, the situation is similar. As shown in Model 3, in addition to leadership willingness, the explanatory power of teachers' trust quality $(\beta=0.160)$ and interpersonal skills $(\beta=0.152)$ also exceed all explanatory variables in the school field, whose maximum is the school common vision $(\beta=0.135)$. The explanatory power of teachers' self-efficacy $(\beta=0.083)$ and self-planning and management ability $(\beta=0.093)$ far exceed other explanatory variables in the school field.

Through further analysis, the 6 variables that reflect teachers' personal factors can be classified into 4 areas: leadership willingness, leadership quality, leadership skills, and professional level (see Figure 2). The relationship between these four aspects and teacher leadership or teacher curriculum leadership has also been explored by other studies. This study confirms and develops some of the conclusions of related researches.

In terms of leadership willingness, Meirink et al. [6] conduct an informal curriculum leadership survey on 12 novice teachers in Dutch middle schools and found that whether teachers can become curriculum leaders not only depends on administrative support, but is also based on the teacher's own leadership motivation and willingness. This is consistent with the conclusion of this study. However, through a large-scale empirical investigation, this study further points out that teachers' curriculum leadership willingness dominates, and its importance far exceeds other external factors.

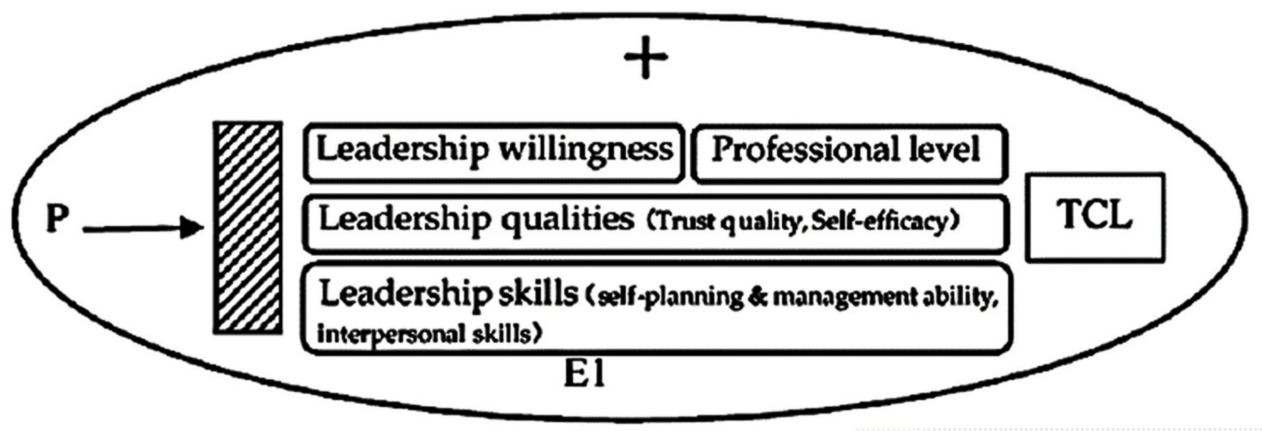

TCL $=$ Teacher curriculum leadership $\mathrm{P}=$ Behavior subject E1 $=$ Individual field factors $t=$ Positive effect Shadow $=$ Obstacle

Figure 2. Schematic diagram of individual field factors influencing teachers' curriculum leadership.

In respect of leadership quality, on the one hand, this study finds that teachers' selfefficacy has a positive predictive effect on their curriculum leadership. Teachers with high self-efficacy have a higher curriculum leadership. On the contrary, if teachers' self-efficacy is low, the curriculum leadership is also low. This finding positively confirms the conclusions 
of related studies. For example, Durias [23] (p. 167-170) points out that teachers' selfconfidence is relevant to curriculum leadership, and if teachers' confidence is insufficient, it will hinder the exertion of leadership ability. Chamberland [9] (p. 104) and Brosky [15] also hold similar views, believing that teachers who lack a positive and calm attitude cannot lead effectively. On the other hand, since leadership is a cooperative enterprise, successful leadership cannot be without the cooperation of leaders and followers. Therefore, the teacher's trust in curriculum stakeholders, such as colleagues, is also a necessary quality. The data of this study shows that teachers who fully value and trust the professional suggestions of colleagues in curriculum decision-making tend to have high development and exercise of their curriculum leadership. In contrast, related researches refer more to the trust of principals or colleagues in teachers, while this study has made a meaningful exploration from another perspective.

For leadership skills, first of all, since leadership is an interpersonal behavior, teachers' interpersonal competence is also an important condition for the use and promotion of their curriculum leadership. A survey study explores the obstacles and support for teachers to implement distributed leadership in Queensland, Australia. In the reflections of 13 teachers participants, the researchers found that teachers' interpersonal skills are one of the facilitating factors of teacher curriculum leadership; especially, actively cooperating with parents can help teachers better exert their leadership skills [19]. This study also finds that the importance of teachers' interpersonal skills ranks among the top three. When the school field factors are not added, its importance is second only to the leadership willingness. After the school field factors are added, its importance is second only to the leadership willingness and trust quality. Secondly, self-planning and management ability to a certain extent represents the teacher's self-leadership, which is also a prerequisite to ensure that teachers can successfully lead other curriculum subjects. Because the development and application of leadership requires a time guarantee, if teachers cannot plan their daily work reasonably, they will have no time to lead because they are stuck in busy work. However, there is less research on this point.

Considering professionalism, as has been revealed by existing researches, teachers who succeed in classroom teaching are more likely to gain the respect and trust of their colleagues, and this kind of respect and trust enable teachers to lead their colleagues more effectively [8]. In addition, professional knowledge and abilities can also promote teachers curriculum decision-making [39]. This study confirms through a large amount of data that the professional level of the curriculum is a basic condition for the teacher's curriculum leadership.

Generally speaking, in terms of teachers' personal factors, this study not only confirms some conclusions of related research, but also gains in-depth insights by using the field dynamic theory as an analysis tool. That is, it firstly confirms the significant predictive effect of the above factors on teacher's curriculum leadership, and at the same time further clarifies the dominant position of teachers' own factors, especially teachers' leadership willingness. This not only provides empirical support in the domain of education for field dynamic theory, but also has important referential value for teacher development policies.

5.1.2. Stimulation of the School Environment Is an Inducing Force for the Development of Teacher Curriculum Leadership

School is the first field of teachers' activities, and has thus become the main space for teachers to adopt and improve curriculum leadership. As shown in Model 2 and Model 3, adding school field factors on the basis of personal factors improves the goodness of fit of the regression model, indicating that when teachers have the internal motivation to exercise and develop curriculum leadership, the school environment plays a positive role in motivating them. This further confirms the view of the field dynamic theory that internal dynamics are dominant and at the same time are controlled by the external environment [38]. However, although school field factors as a whole promote teacher curriculum leadership, not all variables are positively related when viewed separately, and not all variables have an impact on teacher curriculum leadership (see Figure 3). 


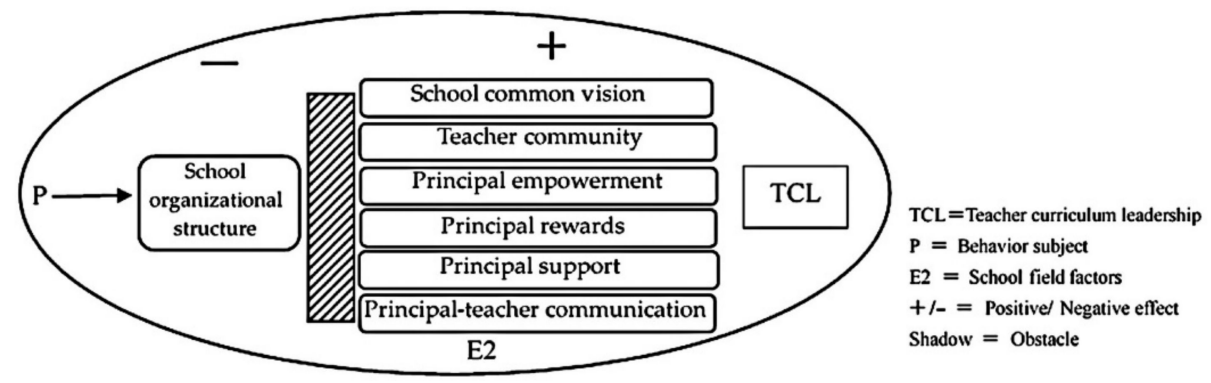

Figure 3. Schematic diagram of school field factors influencing teachers' curriculum leadership.

First of all, school culture (school common vision, cultural atmosphere) is a factor that has attracted much attention in many studies. In this study, school culture is mainly measured by two variables, namely, the school's common vision and the cultural atmosphere. Regression analysis shows that school common vision has a significant positive impact on teachers' curriculum leadership, but the relationship between school cultural atmosphere and teachers' curriculum leadership does not reach statistical significance. This finding can be mutually confirmed in related studies. In terms of shared vision, Brooks et al. [13] negatively state that schools lacking a unified vision will inhibit teachers' curriculum leadership. Studies have also shown positively that the shared vision of the school is conducive to enhancing collaboration, thereby enhancing teachers' improvement and leadership of the school curriculum [12,40]. The conclusion of this study on the relationship between school common vision and teacher curriculum leadership is consistent with the researches above. However, in respect of school cultural atmosphere, this study may confirm the notion that the relationship between the cultural atmosphere and the teacher leadership is uncertain. This is because related researches have reached opposite conclusions. Supporters believe that a cultural atmosphere of mutual trust and cooperation helps to cultivate and develop teachers' curriculum leadership $[17,39]$. The opposite shows that a school culture of collegiality and cooperation is a necessary but insufficient condition for improving teacher leadership [41].

Secondly, the analysis of this study shows that the formation of teacher community plays a positive role in promoting the development of teacher curriculum leadership. This conclusion is also in line with many studies. A study reveals that mutual help between teachers helps them to carry out leadership activities, and when team members are unwilling to follow, it is difficult for teachers to become successful leaders [30]. Tonna and Bugeja [42] show that through the community, teachers are no longer in self-isolation, but can promote the exchange and complementation of the high-quality resources and ideas that each other have, thereby promoting their own teaching improvement and leadership development.

Thirdly, the school organization structure is also a factor that has been often explored. Different school organizational structures have different effects on teachers' curriculum leadership. Generally speaking, a democratic and flat organizational structure helps release teachers' leadership vitality, while hierarchical, top-down or bureaucratic structures inhibit teachers' autonomy and leadership [31,32,43]. However, in this study, the democratic and open school organizational structure- "the school management will fully absorb teachers' opinions in curriculum decision-making" - shows a negative effect on teachers' curriculum leadership. This intriguing result needs more explanations. A study on teachers' participation in joint decision-making finds that the structure of democratic decisionmaking does not necessarily lead to teacher leadership. This is because the teacher's desire to lead in a common decision-making environment is related to his or her perception of risks, costs and potential benefits. In addition, participation in the decision-making process itself is not enough to attract teachers' participation. Teachers need to obtain confirmation that his or her participation does have an impact on decision-making [44]. Looking at the finding of the study from this respect, one possible explanation may be that even though 
the school provides a democratic curriculum decision-making mechanism, teachers may give up participation or choose "surface participation" as they are not sure that their voice will be fully respected and adopted.

Finally, the principal is also an important factor influencing teachers' curriculum leadership. In this study, three principal-related factors, namely, exchanging ideas with teachers on curriculum improvement, providing opportunities for teachers without positions but with outstanding professional abilities to participate in curriculum management and decision-making, and giving appropriate rewards to teachers for their efforts, demonstrate a positive predictive relationship with teacher curriculum leadership. These findings have also received theoretical and empirical support in relevant studies. For example, Meirink et al. [6] and Cheng and Szeto [45] point out that when teachers strive for leadership, the interplay between principal and teacher behavior is very important. Szeto and Cheng [46] also show that the interaction between principal and teachers is the key to the successful development of leadership roles. Buckncr and McDowcllc [47] clearly point out that teacher leadership means the redistribution of school power, whether there are conditions and opportunities to support and encourage teacher leadership in the school affects the practice of teacher leadership, and principal's identification, support and training of teacher leaders play a more significant role. Regarding teacher rewards, some studies have confirmed the findings of this study from the negative side. These studies believe that the lack of rewards or incentives is not conducive to teachers' leadership activities [48] (p.78-106). Wasley [49] (pp.99-102) points out that incentive measures and rewards for teacher leadership must be clear. However, this study finds that the factor that principal provides conditions and support for teachers' professional growth does not show a significant correlation with teacher curriculum leadership. Combining related researches and interviews with teachers in this survey, one possible explanation is that there are other mediating factors between principal's support and teacher's curriculum leadership. Among them, the lack of time for teachers to enact and develop leadership skills is a key factor. In an empirical study on 25 teacher leaders, Ovando [50] finds that participating teachers often use planning and meeting times for leadership activities and lack time and resources to complete the clerical duties involved in leadership work. Although teachers have professional development opportunities, they lack the chance to improve their leadership skills. Similar findings have also been validated in the studies of LeBlanc and Shelton [51], Moller and Katzenmeyer [52], Ovando [50], and Smylie and Denny [53]. In our survey, teachers also frequently mentioned that they "have no time" because the teaching task is already overwhelmed, yet they need to spend more time and energy on family-school communication, and to welcome inspections, etc. This is because the lack of time guarantees that even if the principal creates conditions to support the professional development of teachers, teachers are often unable to make full use of this support.

Based on the analysis above, in terms of school field factors, some of the conclusions of this study further confirm the relevant research findings; but to some extent, it also challenges some inherent consensuses. These confirmations and challenges are equally important for deepening the understanding of school factors that affect teachers' curriculum leadership. At the same time, they provide evidential support for school-level policies to promote teacher curriculum leadership.

\subsection{Effective Strategies to Enhance Teachers' Curriculum Leadership}

The study shows that both the individual and the school fields affect the development of teachers' curriculum leadership, but the influence of the individual field is stronger. Drawing upon the analysis and the results from this study, we try to propose the following strategies that are expected to be effective for teachers' curriculum leadership enhancement.

\subsubsection{Fully Stimulating Teachers' Internal Motivation for Curriculum Leadership}

It can be concluded from this study that teachers' internal motivation for curriculum leadership should be fully stimulated in practice. To achieve this, on one hand, teachers' 
confidence and identity of curriculum leadership should be cultivated through theoretical study and practice, and their psychological field needs should be cared for. The awakening of teachers' curriculum leadership willingness and the shaping of their identity requires teachers to conduct in-depth examination and reflection on their own curriculum practices, so that they can spontaneously and consciously participate in curriculum leadership [54]. On the other hand, the trust quality of teachers should be cultivated and harmonious interpersonal relationships should be built to promote the positive development of teachers' internal motivation. Without trust, teachers may be more inclined to protect themselves than to create relationships with other teachers for better teaching [55]. Good interpersonal relationships can create a comfortable and improved environment, which helps solve problems in reality. Therefore, it is necessary to build an exchange and cooperation platform for teachers on the premise of mutual respect and mutual understanding. In addition, teachers themselves should pay attention to reflection. Reflection can promote democratic interaction and communication among educational stakeholders, so that teachers can become leaders in educational reforms [56,57]. At the same time, teachers can also use professional training or exchanges and cooperation with colleagues to fully tap into the available learning resources and to establish a powerful learning support network that is helpful for personal development.

\subsubsection{Creating a School Environment for Teachers to Exercise Curriculum Leadership}

This study also implies that a school environment for teachers to exercise curriculum leadership should be created in practice. To achieve this, we argue that distributed management mechanisms should be actively explored, true and effective democratic curriculum decision-making should be carried out, and the inducing effect of organizational empowerment should be released. What needs to be made clear is that the "distribution" of distributed leadership is not only in spreading the power and responsibilities of leadership to more people, but in distributing the functions of leadership to people with different expertise (sources of influence), so as to achieve the effect of complementary expertise and synergy [9] (p. 104). In addition, the role of the principal should be changed, the principal should be taken as an important facilitator of teacher curriculum leadership, and the improvement of the culture and work field on which teachers depend should be promoted. The principal is a key element to promote the generation of teachers' curriculum leadership. The development of teachers' curriculum leadership is inseparable from the support and encouragement of the principal [58]. Therefore, principals need to improve their professional abilities, update their educational concepts, and scientifically endow teachers with curriculum powers, shift from traditional administrators to curriculum leaders, and provide teachers with the necessary support. In addition, it is possible to build a professional community by relying on collective lesson preparation and cooperative research to promote the optimization of the atmosphere of mutual help among teachers and the enhancement of joint efforts. Collective lesson preparation and cooperative research are not only an important manifestation of teachers' curriculum leadership practice, but also the core grasp and important support of teachers' professional community, which can provide community support for the development of teachers' curriculum leadership.

\section{Conclusions}

Teacher curriculum leadership can provide sustainable professional support for curriculum reform and student development. Guided by Lewin's field dynamic theory, this study reveals the influencing factors of teachers' curriculum leadership from the perspective of the two levels of mutual influence of the individual field and the school field, through a questionnaire survey and regression analysis of 19,521 Chinese elementary and middle school teachers. On the whole, the personal factors of teachers are the dominant ones affecting their curriculum leadership, and the school environment is an important auxiliary factor. From a field perspective, at the individual field level, teachers' professional level, leadership willingness, leadership qualities, and leadership skills all have significant 
positive impacts on their curriculum leadership, and leadership willingness demonstrates the strongest explanatory power. At the school field level, the school common vision, a community of teachers who help each other, and the principal's communication, empowerment, as well as rewards, are the five specific factors that predict teachers' curriculum leadership. The democratically negotiated curriculum decision-making structure hinders teachers' substantive participation due to the imperfect mechanism (such as teachers' opinions cannot be fully absorbed), thus presenting a negatively predictive relationship with the use of teachers' curriculum leadership.

Compared with existing researches, the possible contributions of this study are as follows: Firstly, the field dynamic theory proposed by Kurt Lewin is used as the analytical framework to explore impacting factors of teacher curriculum leadership from the two interactive fields of the individual and the school, breaking through the static and planar orientation of previous studies. Secondly, focusing on teachers' curriculum leadership in the context of teacher leadership and exploring the factors that influence the development and use of teachers' curriculum leadership and its mechanism have stronger practical significance for the sustainable implementation of curriculum reform. This study also has some limitations. For example, the samples of teachers are not evenly distributed in regions, and the proportion of western provinces far exceeds that of the central and eastern provinces. In the future, it is necessary to increase the investigation of teachers in the central and eastern regions of China, balance the spatial distribution and further enhance the representativeness of the samples, and deeply explore the linkage mechanism between location factors and the development of teacher curriculum leadership. Meanwhile, due to the lack of literature specifically on teacher curriculum leadership, this study mainly initiates dialogue with the study of teacher leadership. As the focused exploration of teachers' curriculum leadership increases, future research will continue to conduct indepth discussions with the related literature.

Author Contributions: Conceptualization, J.C. and Y.Y.; methodology, J.C., F.X., W.X., X.Z. and Y.W.; formal analysis, J.C. and Y.Y.; investigation, F.X., J.C., W.X., X.Z. and Y.W.; writing-original draft preparation, J.C. and Y.Y.; writing-review and editing, J.C., Y.Y. and Y.Z.; visualization, Y.Y.; supervision, Y.Z. All authors have read and agreed to the published version of the manuscript.

Funding: This research was funded by the General Projects of National Philosophy and Social Sciences Foundation of China in 2018 "Study on Curriculum Leadership of Primary and Secondary School Teachers from the Perspective of Key Competencies", grant number BHA180120.

Institutional Review Board Statement: Ethical review and approval were waived for this study, due to that the research does not deal with vulnerable groups or sensitive issues.

Informed Consent Statement: Informed consent was obtained from all participants involved in the study.

Data Availability Statement: The data presented in this study are available on request from the corresponding author. The data are not publicly available due to privacy.

Acknowledgments: Thanks to all the primary and middle school teachers who actively participated in the questionnaire survey for providing reliable data support for this study.

Conflicts of Interest: The authors declare no conflict of interest.

\section{Appendix A}

Questionnaire on Curriculum Leadership of Chinese Primary and Secondary School Teachers

1. Your gender is:

(1) Male (2) Female

2. When did you start working as a teacher?

3. Your school is located at:

(1) Ethnic regions (2) Non-Ethnic regions

4. Your school is located at: 
(1) Urban area (2) Rural area

5. The nature of your school is:

(1) Public school (2) Private school

6. Compared with other schools in this region (city/town/country), what is the ranking of your school in recent two years?

(1) Medium and below medium (2) Above medium (3) Best

7. What subject (s) are you teaching now? (Multiple choice)

(1) Chinese (2) Math (3) English (4) Physics (5) Chemistry (6) Biology

(7) Ethics and Rule of Law/Ideological and Political Course (8) Geography

(9) History/History and Society (10) Music (11) Art (12) Sports \& Health

(13) Information Technology (14) Science (15) Others (please note here)

8. What is your current teaching period?

(1) Primary school (2) Middle school (3) High school

9. Your highest degree is:

(1) Junior high school and below (2) Technical secondary school (3) Technical school

(4) Vocational High School (5) Ordinary high school (6) College degree

(7) Bachelor degree (8) Master degree (9) Doctoral degree

10. Do you have a professional background of teacher education?

(1) Yes (2) No

11. Your current title is:

(1) Unranked (2) Third-level teacher (3) Secondary-level teacher

(4) First-level teacher (5) Advanced teacher (6) Senior teacher

12. Your current concurrent post (s) is/are: (Multiple choice)

(1) None (2) class teacher (3) Lesson preparation team leader

(4) Teaching-research team leader (5) Grade manager (6) Dean/Deputy Dean

(7) Vice-principal (8) Principal (9) Others (please note here)

13. What is the highest award you have received for teaching?

(1) Not yet awarded (2) School level awards (3) County (district) level awards

(4) Municipal awards (5) Provincial awards (6) National awards

14. Please mark " $\sqrt{ }$ " on the column that best meets your actual situation.

\begin{tabular}{ccc}
\hline Items & Strongly Disagree & Disagree Average Agree Strongly Agree \\
\hline
\end{tabular}

(1) You have mastered the advanced and frontier educational concepts and curriculum ideas.

(2) You have mastered the latest national and local curriculum policies, curriculum plans and subject curriculum standards.

(3) You can communicate curriculum policies to students and parents in a timely and appropriate manner.

(4) You lead students, parents or colleagues to work together to form and implement a curriculum vision based on key competencies.

(5) You always carry out unit instructional design based on your overall understanding of the key competencies and the students in your class.

(6) You make full use of existing curriculum resources

(schools, communities, Internet, etc.) to maximize the effect of cultivating students' key competencies.

(7) You discuss and share curriculum schemes based on key competencies with your colleagues.

(8) In your class, most students are highly concentrated and speak enthusiastically. 


\begin{tabular}{lll}
\hline Items & Strongly Disagree & Disagree Average Agree Strongly Agree \\
\hline $\begin{array}{l}\text { (9) You pay attention and respond to the learning needs of } \\
\text { different students. }\end{array}$ & & \\
\hline
\end{tabular}

(10) You make good use of modern information technology in the implementation of the curriculum to guide students to gradually achieve self-development.

(11) You make good use of the products of teaching-research in the implementation of the curriculum to guide students to gradually realize independent development.

(12) You often adjust the teaching progress or method in time according to the teaching reality.

(13) You evaluate the quality of curriculum practice and student development based on the effectiveness of the curriculum vision.

(14) You conduct curriculum evaluation based on teaching data, growth records and other evidence.

(15) You carry out information collection, teaching diagnosis, or curriculum evaluation simultaneously in the teaching process.

(16) You will optimize the curriculum planning based on the results of curriculum reflection.

(17) You meet the individual development needs of students by developing school-based curriculum (undeveloped curriculum please select "strongly disagree").

(18) You are actively developing new curriculum resources to enhance the cultivation effect of students' key competencies (undeveloped curriculum please select "strongly disagree").

(19) You develop curriculum scientifically according to discipline curriculum standards and other relevant regulations (undeveloped curriculum please select "strongly disagree").

(20) After developing a new curriculum, you always invite experts to check the quality (undeveloped curriculum please select "strongly disagree").

(21) You understand the key competencies of Chinese student development.

(22) You understand the key competencies of the teaching subject.

(23) You have a certain understanding of teacher curriculum leadership.

(24) You know how to use curriculum leadership to cultivate students' key competencies.

(25) You know the significance of teacher curriculum leadership for developing students' key competencies.

(26) You believe that teachers as a professional group can and should participate in curriculum leading, management and decision-making. 


\begin{tabular}{|c|c|c|c|c|c|}
\hline Items & Strongly Disagree & Disagree & Average & Agree & Strongly Agree \\
\hline $\begin{array}{l}\text { (27) You believe that only with administrative positions } \\
\text { can teachers enact curriculum leading, management and } \\
\text { decision making. }\end{array}$ & & & & & \\
\hline $\begin{array}{l}\text { (28) You believe that teachers who actively participate in } \\
\text { the construction of the curriculum community are } \\
\text { "curriculum leaders", even if they do not own } \\
\text { administrative positions. }\end{array}$ & & & & & \\
\hline
\end{tabular}

(29) You believe you can and should be involved in curriculum leading, management and decision-making.

(30) You have a strong willingness to lead the curriculum.

(31) You fully value the professional advice of your colleagues in making curriculum decisions.

(32) You believe that with the necessary effort you can effectively accomplish all your tasks.

(33) Even if you are busy at work, you can still plan your daily work reasonably.

(34) You always get support from and cooperation with students, parents, colleagues, leaders or experts in your curriculum practice.

(35) Your school has a high degree of compatibility between the school philosophy, training goals (educational goals) and curriculum aims.

(36) Your school has formed a cultural atmosphere of mutual trust.

(37) In your school, teachers help each other and develop cooperatively.

(38) In your school, the management level will take teachers' opinions into account when making curriculum decisions.

(39) Your principal provides sufficient conditions for the professional growth of teachers.

(40) Your principal often exchanges ideas on curriculum improvement with different teachers.

(41) Your principal provides opportunities for teachers who do not have positions but have outstanding professional abilities to participate in curriculum management and decision-making.

(42) Your principal will give appropriate rewards to teachers for their efforts.

\section{References}

1. Edge, K.; Mylopoulos, M. Creating cross-school connections: LC networking in support of leadership and instructional development. Sch. Leadersh. Manag. 2008, 28, 147-158. [CrossRef]

2. Beachum, F.; Dentith, A.M. Teacher leaders creating cultures of school renewal and transformation. Educ. Forum 2004, 68, 276-286. [CrossRef]

3. Singh, A.; Yager, S.O.; Yutakom, N.; Yager, R.E.; Ali, M.M. Constructivist teaching practices used by five teacher leaders for the Iowa Chautauqua professional development program. Int. J. Environ. Sci. Educ. 2012, 7, 197-216. [CrossRef]

4. Wenner, J.A.; Campbell, T. The Theoretical and Empirical Basis of Teacher Leadership: A Review of the Literature. Rev. Educ. Res. 2017, 87, 134-171. [CrossRef]

5. Cherkowski, S. Positive Teacher Leadership: Building Mindsets and Capacities to Grow Wellbeing. Int. J. Teach. Leadersh. 2018, 9 , 63-78. [CrossRef] 
6. Meirink, J.; Want, A.; Louws, M.; Meijer, P.; Marchand, H.; Schaap, H. Beginning teachers' opportunities for enacting informal teacher leadership: Perceptions of teachers and school management staff members. Eur. J. Teach. Educ. 2020, 43, 243-257. [CrossRef]

7. Lai, E.; Cheung, D. Enacting teacher leadership: The role of teachers in bringing about change. Educ. Manag. Adm. Leadersh. 2015, 43, 673-692. [CrossRef]

8. York-Barr, J.; Duke, K. What do we know about teacher leadership? Findings from two decades of scholarship. Rev. Educ. Res. 2004, 74, 255-316. [CrossRef]

9. Chamberland, L. Distributed Leadership: Developing a New Practice: An Action Research Study; ProQuest Dissertations \& Theses Global: Santa Cruz, CA, USA, 2009; p. 104.

10. Gigante, N.A.; Firestone, W.A. Administrative support and teacher leadership in schools implementing reform. J. Educ. Adm. 2008, 46, 302-331. [CrossRef]

11. Adams, D.; Gamage, D.T. A study of leadership effectiveness in a large VET institution in Australia. Int. J. Educ. Manag. 2008, 22, 214-228. [CrossRef]

12. Hart, A.W. Creating teacher leadership roles. Educ. Adm. Q. 1994, 30, 472-497. [CrossRef]

13. Brooks, J.S.; Scribner, J.P.; Eferakorho, J. Teacher leadership in the context of whole school reform. J. Sch. Leadersh. 2004, 14, 242-265. [CrossRef]

14. Podjasek, H.L. The Space Between: Women Teachers as Leaders; ProQuest Dissertations \& Theses Global: Santa Cruz, CA, USA, 2009; pp. 20-24.

15. Brosky, D. Micropolitics in the school: Teacher leaders' use of political skill and influence tactics. Int. J. Educ. Leadersh. Prep. 2011, $6,1-11$.

16. Zinn, U.F. Supports and Barriers to Teacher Leadership: Reports of Teacher Leaders; ProQuest Dissertations Publishing: Greeley, CO, USA, 1991; p. 59.

17. Muijs, D.; Harris, A. Teacher led school improvement: Teacher leadership in the UK. Teach. Teach. Educ. 2006, 22, 961-972. [CrossRef]

18. Klinker, J.F.; Watson, P.A.; Furgerson, P.; Halsey, P.; Janisch, C. "Tipping” teachers toward change: Developing leadership characteristics through book club. Teach. Educ. Pract. 2010, 23, 103-119.

19. O'Gorman, L.; Hard, L. Looking Back and Looking Forward: Exploring Distributed Leadership with Queensland Prep Teachers. Australas. J. Early Child. 2013, 38, 77-84. [CrossRef]

20. Shen, J.; Wu, H.; Reeves, P.; Zheng, Y.; Ryan, L.; Anderson, D. The association between teacher leadership and student achievement: A meta-analysis. Educ. Res. Rev. 2020, 31, 100357. [CrossRef]

21. Sinha, S.; Hanuscin, D.L. Development of teacher leadership identity: A multiple case study. Teach. Teach. Educ. 2017, 63, 356-371. [CrossRef]

22. Carpenter, B.D.; Sherretz, C.E. Professional development school partnerships: An instrument for teacher leadership. Sch. Univ. Partnersh. 2012, 5, 89-101.

23. Durias, R.F. Teacher Leaders of Color: The Impact of Professional Development on Their Leadership; ProQuest Dissertations \& Theses Global: Santa Barbara, CA, USA, 2010; pp. 4, 155, 167-170.

24. Burnes, B.; Cooke, B. Kurt Lewin's Field Theory: A Review and Re-evaluation. Int. J. Manag. Rev. 2013, 15, 408-425. [CrossRef]

25. Lewin, K. Resolving Social Conflicts; Harpper and Brother Publishers: New York, NY, USA, 1948; p. 11.

26. Lewin, K. Field Theory in Social Science; Harpper and Brother publishers: New York, NY, USA, 1951; pp. $239-240$.

27. Harris, A.; Muijs, D. Improving Schools through Teacher Leadership; Open University Press: Maidenhead, UK, $2005 ;$ p. 106.

28. Ramrathan, L.; Ngubane, T.I. Instructional leadership in multigrade classrooms: What can monograde teachers learn from their resilience? Educ. Chang. 2013, 17, S93-S105. [CrossRef]

29. Muijs, D.; Harris, A. Teacher leadership-Improvement through empowerment? An overview of the literature. Educ. Manag. Adm. Leadersh. 2003, 31, 437-448.

30. Margolis, J.; Doring, A. The fundamental dilemma of teacher leader-facilitated professional development: Do as I (kind of) say, not as I (sort of) do. Educ. Adm. Q. 2012, 48, 859-882. [CrossRef]

31. Pellicer, L.Q.; Anderson, L.W. A Handbook for Teachers; Conwin Press: Thousand Oaks, CA, USA, $1995 ;$ pp. 16-17.

32. Frost, D.; Harris, A. Teacher Leadership: Towards a Research Agenda. Camb. J. Educ. 2003, 33, 479-498. [CrossRef]

33. Childs-Bowen, D.; Moller, G.; Scrivner, J. Principals: Leaders of Leaders. NASSP Bull. 2000, 84, 27-34. [CrossRef]

34. Gordin, L. Conceptualization and Support of the Role of Teachers Serving as Team Leaders in a Professional Learning Community; ProQuest Dissertations \& Theses Global: Santa Barbara, CA, USA, 2010; p. 145.

35. Borchers, B.T. A Study to Determine the Practices of High School Principals and Central Office Administrators Who Effectively Foster Continuous Professional Learning in High Schools; ProQuest Dissertations \& Theses Global: Santa Barbara, CA, USA, 2009 ; p. 108.

36. Teaching and Research Office of Shanghai Municipal Education Commission. Curriculum Leadership: The Engine of School Sustainable Development: Shanghai's 10-Year Action to Improve Curriculum Leadership in Primary and Secondary Schools (Kindergarten); Shanghai Scientific and Technological Education Publishing House: Shanghai, China, 2019; p. 13.

37. Teacher Questionnaire of China Education Panel Survey in School Year 2014-2015. 2014. Available online: http:/ / ceps.ruc.edu. cn/_local/1/00/98/AB062E7F7744BAB168F8981D4EC_05E32002_42760.pdf?e=.pdf (accessed on 17 May 2021). 
38. Elie-Dit-Cosaque, C.; Pallud, J.; Kalika, M. The Influence of Individual, Contextual, and Social Factors on Perceived Behav-ioral Control of Information Technology: A Field Theory Approach. J. Manag. Inf. Syst. 2011, 28, 201-234. [CrossRef]

39. Dora, C.W.H. Teacher participation in curriculum and pedagogical decisions: Insights into curriculum leadership. Educ. Manag. Adm. Leadership. 2010, 38, 613-624. [CrossRef]

40. Zhan, X.; Anthony, A.B.; Goddard, R.; Beard, K. Development, factor structure, and reliability of the Shared instructional Leadership Scale in public secondary schools. Educ. Manag. Adm. Leadersh. 2020, 1-20. [CrossRef]

41. Smylie, M.A. Teachers' reports of their interactions with teacher leaders concerning classroom instruction. Elem. Sch. J. 1992, 93, 85-98. [CrossRef]

42. Tonna, M.A.; Bugeja, G. Evaluating a Train the Trainer programme and the way this empowers educators to bring about systemic change. Eur. J. Teach. Educ. 2018, 41, 496-516. [CrossRef]

43. Institute for Educational Leadership. Leadership for Student Learning: Redefining the Teacher as Leader; Institute for Educational Leadership, Inc.: Washington, DC, USA, 2001.

44. Duke, D.L.; Showers, B.K.; Imber, M. Teachers and shared decision making: The costs and benefits of involvement. Educ. Adm. $Q$. 1980, 16, 93-106. [CrossRef]

45. Cheng, A.; Szeto, E. Teacher Leadership development and principal facilitation: Novice teachers' perspectives. Teach. Teach. Educ. 2016, 58, 140-148. [CrossRef]

46. Szeto, E.; Cheng, A. Principal-teacher interactions and teacher leadership development: Beginning teachers' perspectives. Int. J. Leadersh. Educ. 2018, 21, 363-379. [CrossRef]

47. Buckncr, K.U.; McDowcllc, J.O. Developing teacher leaders; Providing encouragement, opportunities, and support. NASSP Bull. 2000, 84, 35-41. [CrossRef]

48. Little, J.W. Assessing the prospects for teacher leadership. In Building a Professional Culture in Schools; Lieberman, A., Ed.; Teachers College Press: New York, NY, USA, 1988; pp. 78-106.

49. Wasley, P.A. Teachers Who Lead: The Rhetoric of Reform and The Realities of Practice; Teachers College Press: New York, NY, USA, 1991; pp. 99-102.

50. Ovando, M.N. Teacher leadership: Opportunities and challenges. Plan. Chang. 1996, 27, 30-44.

51. LeBlanc, P.R.; Shelton, M.M. Teacher leadership: The needs of teachers. Action Teach. Educ. 1997, 19, 32-48. [CrossRef]

52. Moller, G.; Katzenmeyer, M. The promise of teacher leadership. New Dir. Sch. Leadersh. 1996, 1, 1-17.

53. Smylie, M.A.; Denny, J.W. Teacher leadership: Tensions and ambiguities in organizational perspective. Educ. Adm. Q. 1990, 26, 235-259. [CrossRef]

54. Chew, J.O.A.; Andrews, D. Enabling teachers to become pedagogical leaders: Case studies of two IDEAS schools in Singapore and Australia. Educ. Res. Policy Pract. 2010, 9, 59-74. [CrossRef]

55. Tschannen-Moran, M.; Hoy, W.K. A Multidisciplinary Analysis of the Nature, Meaning, and Measurement of Trust. Rev. Educ. Res. 2000, 70, 547-593. [CrossRef]

56. Salleh, H.; Tan, C. Habermas and teacher leadership through reflection. New Educ. Rev. 2008, 15, 114-125.

57. Liu, K. Critical reflection as a framework for transformative learning in teacher education. Educ. Rev. 2015, 67, 135-157. [CrossRef]

58. Klar, H.W.; Huggins, K.S.; Hammonds, H.L.; Buskey, F.C. Fostering the capacity for distributed leadership: A post-heroic approach to leading school improvement. Int. J. Leadersh. Educ. 2016, 19, 111-137. [CrossRef] 